\title{
Hot Water Treatment in Combination with Rachis Removal and Modified Atmosphere Packaging Maintains Quality of Table Grapes
}

\author{
Liping Kou ${ }^{1}$ \\ College of Food Science and Engineering, Northwest A\&F University, 28, \\ Xinong Road, Yangling, Shaanxi, 712100, China; and Produce Quality and \\ Safety Laboratory, USDA ARS, 10300 Baltimore Avenue, Beltsville, MD \\ 20705
}

\section{Yaguang Luo}

Produce Quality and Safety Laboratory, USDA ARS, 10300 Baltimore Avenue, Beltsville, MD 20705

\author{
Wu Ding and Xinghua Liu \\ College of Food Science and Engineering, Northwest A\&F University, 28, \\ Xinong Road, Yangling, Shaanxi, 712100, China
}

\section{William Conway}

Produce Quality and Safety Laboratory, USDA ARS, 10300 Baltimore Avenue, Beltsville, MD 20705

Additional index words. hot water, microbial growth, sensory, chlorine, packaging, table grapes, sulfur dioxide

\begin{abstract}
Alternatives to sulfur dioxide to maintain quality of table grapes, including various combinations of rachis removal, chlorinated wash, hot water treatment, and modified atmosphere packaging, were explored in this study. Grapes were prepared by cutting off the rachis 1 to $2 \mathrm{~mm}$ from the fruit or by keeping the clusters intact. After initial preparation, short-stem and cluster grapes were subjected to chlorinated wash and/or hot water $\left(45^{\circ} \mathrm{C}, 8 \mathrm{~min}\right)$ treatment and packaged in plastic trays sealed with a gaspermeable film. The treated grapes as well as the commercially packed grapes (COM) in their original packages were stored at $5{ }^{\circ} \mathrm{C}$ for up to 4 weeks. Hot water treatment resulted in significantly $(P<\mathbf{0 . 0 5})$ higher oxygen retention and lower carbon dioxide accumulation in package headspaces, maintained a firmer texture, higher overall visual quality, lower decay rate, and lower microbial populations than other treatments or COM during the entire storage period. Grapes that were cut from the rachis and treated with hot water and chlorine maintained the highest quality for 4 weeks with the least decay among all treatments. A chlorine prewash treatment significantly $(P<0.05)$ reduced microbial populations on cluster grapes and maintained better overall quality. Conventional COM grapes developed dark decay and lost turgidity and were of unacceptable quality at $\mathbf{2 8}$ days of storage.
\end{abstract}

Packaged fresh-cut grapes are emerging as a ready-to-eat convenient food snack. Tissue injuries incurred during the grape preparation process in which the stems are manually pulled off of the grapes result in fresh-cut grapes having a shelf life of only $14 \mathrm{~d}$. Increased microbial growth, decay development, and loss of firmness are major problems that reduce the quality and shelf life of freshcut grapes.

\footnotetext{
Received for publication 13 Apr. 2009. Accepted for publication 8 Oct. 2009 .

We thank Ellen Turner for dedicated technical support and Willard Douglas for assistance in gas composition measurement.

${ }^{1}$ To whom reprint requests should be addressed; e-mail Kouliping8@hotmail.com.
}

Commercially packaged table grapes that are stored in clusters in perforated packaging also have a short shelf life, typically 8 to 10 weeks, as a result of their exposure to the environment, but this varies greatly with storage conditions and grape variety and can be anywhere from 2 weeks to 6 months (Franke, 2006). The shelf life of these grapes is often shortened by weight loss, stem browning, softening, shattering, and decay (Crisoto et al., 2001; Perkins-Veazie et al., 1992). The standard method to control postharvest decay of cluster grapes is to fumigate the fruit immediately after harvest with sulfur dioxide gas followed by additional sulfur dioxide application during storage using either direct gas treatment or fumigation through continuous-release sulfur dioxide $\left(\mathrm{SO}_{2}\right)$-generating pads. However, the con- centration of sulfur dioxide necessary to inhibit fungal growth may induce injuries in both rachis and berries (Crisoto and Mitchell, 2002). In addition, sulfite residues pose a health risk for allergic individuals and its applications have been restricted in many countries (Lurie et al., 2006). Therefore, safe alternative technologies are needed to control fungal growth and assure high-quality fruit.

Heat treatments of harvested fruits have been useful for controlling insect infestation and decay as well as for delaying ripening and modifying fruit responses to stress (Lurie, 1998; Paull and Chen, 2000). Several investigators have reported the beneficial effect of immersion in hot water to control postharvest diseases for various fruits other than table grapes, including guava, kiwifruit, strawberry, citrus fruits, and cactus pear (Barkai-Golan and Philips, 1991; Cheah et al., 1992; Garcia et al., 1995; Jacobi and Wong, 1992; Madhukar and Reddy, 1990; Schirra et al., 1996; Schirra and BenYehoshua, 1999). Lydakis and Aked (2003) found that vapor heat treatment of grapes at $52.5^{\circ} \mathrm{C}$ for 21 to $24 \mathrm{~min}$ or at $55^{\circ} \mathrm{C}$ for 18 to 21 min reduced fungal infection. However, vapor heat sometimes damages the fruit, whereas the slower heat transfer and lower humidity of forced hot air causes less damage (Lurie, 1998). Lurie found that by applying a moderate heat treatment, ripening could be delayed and fungal decay reduced without major changes in fruit quality. Kou et al. (2006a, 2006b) found that $45^{\circ} \mathrm{C}$ for $8 \mathrm{~min}$ and $55{ }^{\circ} \mathrm{C}$ for $5 \mathrm{~min}$ provided, respectively, the best hot water and hot air treatments for table grapes. They also discovered that hot water treatment was preferable to hot air treatment (Kou et al., 2007).

Although grape berries are nonclimacteric fruits and have low respiration rates, the grape pedicels and stalks behave in a climacteric manner having respiration rates 10 times that of the berries (Deng et al., 2007; Wu et al., 1992). The rachis is also vulnerable to dehydration and fungal infection during postharvest handling and storage. Sulfur dioxide gas $\left(\mathrm{SO}_{2}\right)$ is currently the treatment of choice in many countries for prolonging shelf life of grapes, because it delays stem browning and decay. In our previous study, we found that cutting grape pedicels 1 to $2 \mathrm{~mm}$ from the fruit had the potential to reduce respiration rate, water loss, and fungal growth (Kou et al., 2007). This approach eliminated the problems associated with leaving the fruit on the rachis as well as those caused by pulling grapes off of the pedicel. Furthermore, hot water treatment was also found to be more beneficial than hot air treatment in maintaining fresh-cut grape quality.

The main objectives of this study were to optimize a treatment for cluster grapes as an alternative to sulfur dioxide to maintain quality of table grapes. The combination or sequential treatments of cutting the rachis 1 to $2 \mathrm{~mm}$ from the berries, sanitized wash, hot water treatment, modified atmosphere packaging (MAP) technologies for reducing decay and microbial growth, and maintaining 
grape quality during $5{ }^{\circ} \mathrm{C}$ storage were tested. Grapes treated according to chosen conditions were compared with commercially packaged cluster grapes.

\section{Materials and Methods}

Sample preparation. Fresh table grapes (Vitis vinifera L., cv. Crimson) were obtained from a wholesale produce market in Jessup, MD. The grapes were transported (within 30 min) to the Product Quality and Safety Laboratory (Beltsville, MD) and used immediately. A total of seven treatments were designated as follows: 1) S-C-H: short-stem grapes receiving chlorine wash and hot water treatment; 2) S-C-NH: short-stem grapes receiving chlorine wash and no hot water treatment; 3) B-C-H: cluster grapes receiving chlorine and hot water treatment; 4) B-C-NH: cluster grapes receiving chlorine but no hot water treatment; 5) B-NC-H: cluster grapes receiving no chlorine but hot water treatment; 6) B-NC-NH: cluster grapes not receiving either chlorine or hot water treatment; and 7) COM: commercially packed cluster grapes.

Rachis removal versus cluster grapes. The grapes were prepared using the following two methods: 1) the rachis of the grapes was removed by cutting short the pedicels with a pair of sanitized scissors so that the grapes retained 1 to $2 \mathrm{~mm}$ of pedicel ( $\mathrm{S}$ for short-stem); and 2) the rachis and pedicels of cluster grapes were kept intact and the grapes remained on the original cluster (B for bunch grapes).

Chlorine wash and hot water treatments. Grapes of both cluster and short-stem treatment groups were placed into clean mesh bags (Linens N' Things, Clifton, NJ). The samples were then dipped in $100 \mu \mathrm{L} \cdot \mathrm{L}^{-1}$ sodium hypochlorite $(\mathrm{pH}$ 6.5) solution (C) or water (NC) for $1 \mathrm{~min}$ followed by draining and air drying. A portion of the samples was then subjected to a mild heat treatment by immersing the bags in a water bath at $45^{\circ} \mathrm{C}$ for 8 min followed by draining and air cooling. Care was taken to ensure that all berries were completely submerged in the water during the hot water treatment. Because short-stem grapes were considered in the category of fresh-cut grapes, they were treated as a ready-to-eat product and were all subjected to chlorine wash.

Modified atmosphere packaging and storage. After heat treatment, short-stem $(\approx 300 \mathrm{~g})$ and cluster grape samples $(\approx 450$ g) were put into $16.9 \times 22.3 \times 2.9 \mathrm{~cm}$ and $16.9 \times 22.3 \times 7.6-\mathrm{cm}$ rigid polypropylene trays (Pactiv Corporation, Lake Forest, IL), respectively, and sealed with a 29.2 $\mathrm{pmol} \cdot \mathrm{s}^{-1} \cdot \mathrm{m}^{-2} \cdot \mathrm{Pa}^{-1}$ oxygen transmission rate film (Packaging Concept Inc., Salinas, CA). Commercially packed grapes (COM) maintained in their original packaging conditions [vented bags placed in wooden crates with plastic perforated bottom (1/4-inch holes) containing slow-release sulfur dioxide generating pads] were used for comparison with experimental ones. All samples were stored at $5 \pm 1{ }^{\circ} \mathrm{C}$ for up to $28 \mathrm{~d}$ with quality evaluations performed on Days $0,7,14$, and 28. A total of three replications were tested for each treatment.

Package atmosphere and product quality evaluation. Headspace gas samples were withdrawn from the packages on Days 7 , 14, and 28 using a gas-tight syringe. The gas samples were injected into an $\mathrm{N}_{2}$ stream $\left(2.5 \mathrm{~mL} \cdot \mathrm{s}^{-1}\right.$ flow rate) connected to an $\mathrm{O}_{2}$ analyzer (S-3A/II with a calcium-zirconia electrochemical detection cell; Ametek Co., Thermox Instruction Analytical Division, Pittsburgh, PA) and an infrared $\mathrm{CO}_{2}$ analyzer (ADC 225-Mk3; Analytical Development Co., Hertfordshire, UK). Headspace $\mathrm{C}_{2} \mathrm{H}_{4}$ was determined using a glass gas-tight syringe $(0.5-\mathrm{mL}$ Gastight 1750; Hamilton Co., Reno, NV) to withdraw duplicate $0.2-\mathrm{mL}$ samples from the headspace of each package. The samples were injected into a gas chromatograph (HP 5890A; Hewlett Packard, Golden, CO) equipped with a GS-Q column $(3.0 \mathrm{~m} \times 0.53 \mathrm{~mm}$; J \& W Scientific, Folsom, $\mathrm{CA}$ ) and a flame ionization detector. The flow velocity of carrier gas (nitrogen) was 0.5 $\mathrm{mL} \cdot \mathrm{s}^{-1}$. Detector, oven (column), and injector were operated at 250,70 , and $200{ }^{\circ} \mathrm{C}$, respectively, according to Kim et al. (2005).

Texture measurements were conducted on 30 decay-free grapes from each replication. The compression firmness of grapes was determined using a texture analyzer (Model TA-XT2; Texture Technologies Corp., Scarsdale, NY) using a 38-mm diameter cylindrical probe to a deformation of $10 \mathrm{~mm}$ at $2.0 \mathrm{~mm} \cdot \mathrm{s}^{-1}$. The peak force (Fmax) was recorded and expressed as the firmness of the grapes.

Decay rate was calculated as the percentage of grapes showing any visible decay in each package (Valero et al., 2006). A panel of five trained personnel evaluated overall visual quality after $28 \mathrm{~d}$ of storage using a 9point hedonic scale, in which $9=$ like extremely; $7=$ like moderately; $5=$ neither like nor dislike; 3 = dislike moderately; and $1=$ dislike extremely (Meilgaard et al., 1991). The samples were coded with threedigit numbers to mask the treatment identity in an effort to minimize subjectivity and ensure test accuracy.

Microbial enumeration. Microbial samples were taken by cutting 16 randomly selected grapes from each replicate into four parts and using approximately one-fourth of each cut grape totaling $\approx 25 \mathrm{~g}$ of grape tissue per replicate sample. Triplicate samples taken per treatment were macerated in 225 $\mathrm{mL}$ phosphate-buffered saline with a stomacher (Model 400; Seward Medical, London, UK) for $1 \mathrm{~min}$ at $260 \mathrm{rpm}$. The filtrate and its appropriate dilutions were logarithmically plated on agar plates with an automatic spiral plater (Autospiral ${ }^{\text {TM }}$; Don Whitley Scientific Ltd., West Yorkshire, UK). Enumeration of micro-organisms was performed using the following culture media and conditions: 1) tryptic soy agar (Difco Laboratory, Sparks, MD) incubated at $30^{\circ} \mathrm{C}$ for 24 to $48 \mathrm{~h}$ for the enumeration of total aerobic mesophilic bacteria; 2) potato dextrose agar (Difco
Laboratory) supplemented with $200 \mathrm{~g} \cdot \mathrm{mL}^{-1}$ chloramphenicol incubated at $28^{\circ} \mathrm{C}$ for $48 \mathrm{~h}$ for the enumeration of yeasts and molds; and 3) Lactobacilli Man-Rogosa-Sharpe agar (Difco Laboratory) incubated at $30{ }^{\circ} \mathrm{C}$ for $72 \mathrm{~h}$ under $20 \mathrm{kPa} \mathrm{CO}$ and $5 \mathrm{kPa} \mathrm{O}_{2}$ for the enumeration of lactic acid bacteria (LABORATORY). Microbial colonies were counted using a Protos Colony Counter (Model 50000; Synoptics, Cambridge, UK) and reported as log cfu/gram of tissue.

Experimental design and statistical analysis. The layout of the experiment was according to a completely randomized design with three replications. Preliminary experiments were conducted before the experiment reported here. Product quality and package atmospheres were measured on Days 7, 14, and 28 during storage and product quality was additionally measured on Day 0 . All quality evaluations were performed in a temperaturecontrolled room at $5{ }^{\circ} \mathrm{C}$ to minimize the effect of temperature variation during testing. Data were analyzed as a two-factor linear model using the PROC MIXED procedure (SAS Institute Inc., Cary, NC) with seven levels of grape treatment (S-C-H, S-C-NH, $\mathrm{B}-\mathrm{C}-\mathrm{H}, \quad \mathrm{B}-\mathrm{C}-\mathrm{NH}, \quad \mathrm{B}-\mathrm{NC}-\mathrm{H}, \quad \mathrm{B}-\mathrm{NC}-\mathrm{NH}$, $\mathrm{COM}$ ) as one factor and storage duration as the other factor. When effect(s) were statistically significant, mean comparisons were done with Sidak-adjusted $P$ values so that the experimentwise error was $\leq 0.05$.

\section{Results and Discussion}

Gas composition. Oxygen partial pressures in the headspace of the packages decreased significantly $(P<0.05)$ during storage (Fig. 1A). All chlorine-treated cluster and short-stem grapes showed similar trends in the changes in $\mathrm{O}_{2}$ partial pressures during storage. However, packages containing cluster grapes that had received hot water treatment (B-NC-H; $11.5 \quad \mathrm{kPa} \mathrm{O}_{2}$ ) retained a significantly higher $\mathrm{O}_{2}$ partial pressure than cluster grapes that had received no chlorine treatment (B-NC-NH; $4 \mathrm{kPa} \mathrm{O}_{2}$ ) after $28 \mathrm{~d}$ of storage. This is attributable to the reduced respiration rate of grapes receiving hot water treatment.

The changes in $\mathrm{CO}_{2}$ partial pressure (Fig. 1B) followed a reverse trend in comparison with $\mathrm{O}_{2}$. Hot water treatment significantly reduced the accumulation in $\mathrm{CO}_{2}$ partial pressure on unsanitized cluster grapes compared with those that did not receive hot water treatment, especially after 14 and $28 \mathrm{~d}$ of storage. Cluster grapes that received chlorine treatment also displayed a similar beneficial effect of hot water treatment in reducing $\mathrm{CO}_{2}$ accumulation compared with those that received no heat treatment, especially after 14 and $28 \mathrm{~d}$ of storage. This result is consistent with the finding previously reported by Alique et al. (2005) for hot water-treated sweet cherry.

The benefit of hot water treatment in maintaining lower tissue metabolic rate is also evident in its effect on ethylene production (Fig. 1C), especially after $7 \mathrm{~d}$ of 


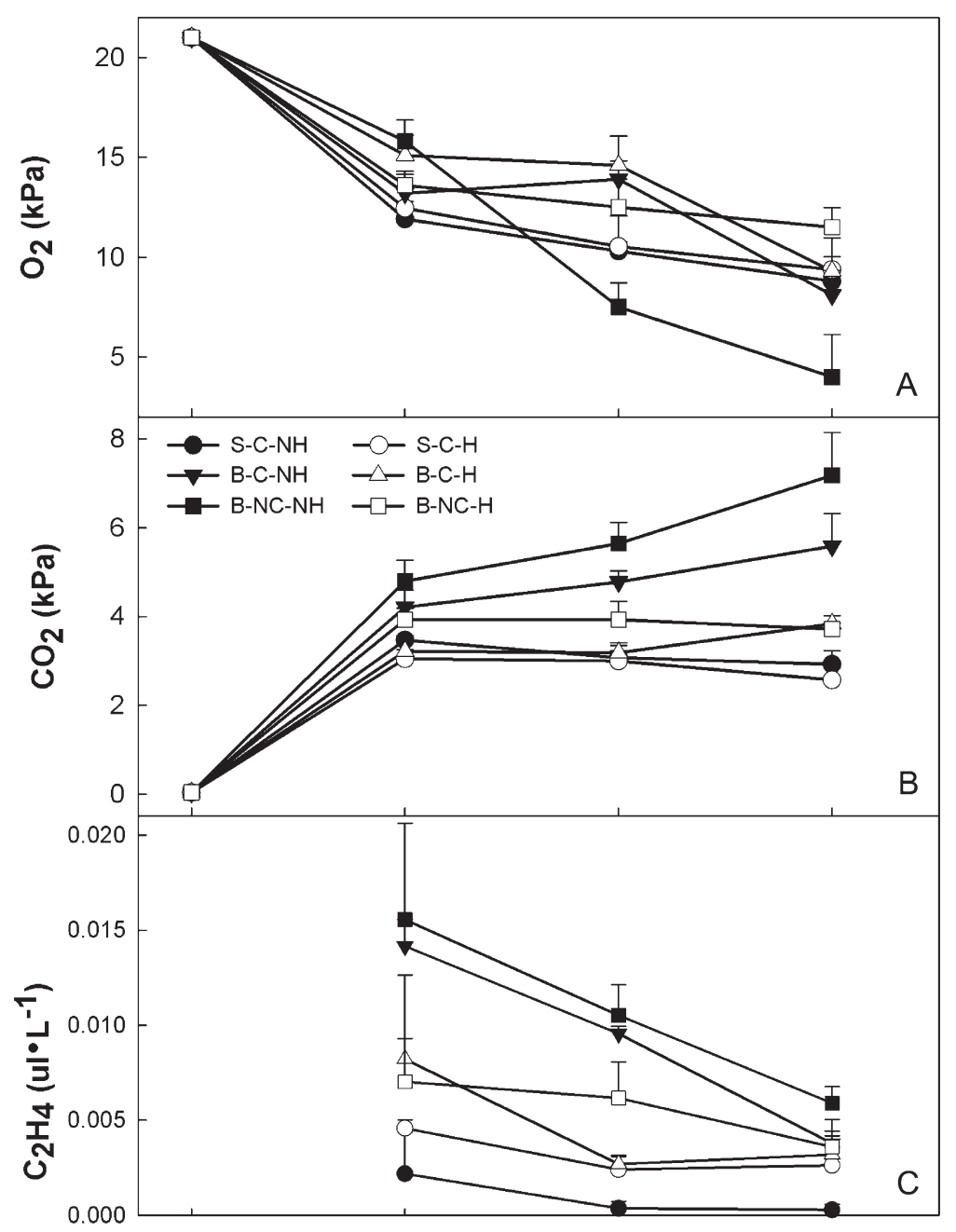

Storage time (d)

Fig. 1. Partial pressures of $\mathrm{O}_{2}(\mathbf{A}), \mathrm{CO}_{2}(\mathbf{B})$, and $\mathrm{C}_{2} \mathrm{H}_{4}(\mathbf{C})$ in the packages containing short-stem and cluster grapes during $5{ }^{\circ} \mathrm{C}$ storage. Vertical bars represent the SE of the mean of three replications. S-C-NH $=$ short-stem grapes that received chlorine wash and no heat treatment; $\mathrm{S}-\mathrm{C}-\mathrm{H}=$ short-stem grapes with chlorine wash and hot water treatment; $\mathrm{B}-\mathrm{C}-\mathrm{H}=$ cluster grapes that received chlorine and hot water treatment; B-C-NH = cluster grapes that received chlorine but no heat treatment; B-NC-H = cluster grapes that received no chlorine treatment but did receive hot water treatment; $\mathrm{B}-\mathrm{NC}-\mathrm{NH}=$ cluster grapes that did not receive either chlorine or hot water treatment.

storage. Samples that had received hot water treatment had significantly lower ethylene partial pressure in the headspace of the packages than their corresponding treatment without hot water regardless of whether they had received chlorine treatment. However, chlorine treatment had no effect on ethylene partial pressures.

Texture. Grapes from MAP trays retained significantly $(P<0.001)$ greater firmness than commercially packaged grapes during the 28-d storage period (Fig. 2A). The lower firmness reading is probably the result of senescence and/or lack of turgidity resulting from water loss of grapes when stored in the unsealed commercial packages; the senescence of grapes leads to softening. For cluster grapes that received no sanitation treatment, hot water treatment maintained a significantly greater firmness than those that received no hot water treatment on Days 14 and 28 . However, for cluster samples that received chlorine treatment, there was no difference in firmness with or without hot water treatment throughout the storage. Heating to temperatures in the range of 52 to $65^{\circ} \mathrm{C}$ has been found to allow demethylation of pectin by pectinmethylesterase to form anionic carboxyl groups with which calcium can form salt bridge links, thereby strengthening cell walls (Alonso et al., 1997) and rendering them less accessible to the enzymes that cause softening (Sams et al., 1993). This process can be augmented by adding calcium chloride, but it occurs also with calcium that is naturally present in fruit and vegetable tissues. A variety of fruits, including apples, strawberries, muskmelon, and tomatoes, have been shown to benefit from the combined calcium and heat treatment, or heat treatment alone, in terms of increased firmness and/or decay resistance and extended shelf life (Fallik et al., 2001; Garcia et al., 1995; Klein et al.,1995; Lamikanra et al.,
2005; Lamikanra and Watson, 2007; Lara et al., 2006; Luna-Guzman et al., 1999; Lurie and Klein, 1992; Lurie and Sabehat, 1997). A number of researchers have hypothesized the formation of salt bridges as a result of enzyme activity in postharvest fruits to be the reason for their increased firmness after low-temperature heat treatment. Although this effect has not specifically been demonstrated in grapes, calcium is ubiquitous in plant cells, including grape tissues, playing a central role in signal transduction and ion exchange transport, which specifically occurs in grape skin. It is therefore hypothesized that a mild treatment could also benefit the firmness of grapes.

Decay rate. Grapes stored in MAP-sealed trays maintained a significantly $(P<0.001)$ lower decay rate than commercially packaged grapes (COM) from the period of storage between Days 14 and 28 except BNC-NH (Fig. 2B), which is consistent with the findings previously reported by ArtésHernández et al. (2006). The treatment BNC-NH had the highest decay rate on Day 28 , probably as a result of the lack of sanitizer or hot water treatment to inhibit fungal growth accompanied by moist conditions in the MA packaging, which created an environment conducive to mold growth. Commercially packaged bags have many large perforations that allow water evaporation. Thus, the rachis and berries in this treatment experienced a higher degree of dehydration than in others.

Whether cluster grapes received chlorine treatment, those that received hot water treatment maintained a significantly lower decay rate on Days 14 and 28 than those that had not received hot water treatment. It was especially noted that the decay rate of hot water-treated $(\mathrm{B}-\mathrm{NC}-\mathrm{H})$ cluster grapes was significantly $(P<0.001)$ lower than that of nonheat-treated (B-NC-NH) corresponding grapes on Day 28. The short-stem grape treatment groups (S-C-NH and S-C-H) had fewer decayed berries $(4.8 \%$ and $1.5 \%$, respectively, on Day 28) than cluster grape treatment groups (B-C-NH and B-C-H), but no significant difference was found between them. For cluster grapes that received no hot water treatment, chlorine treatment maintained a significantly $(P<0.001)$ lower decay rate than those that received no sanitation treatment on Day 28, indicating that chlorine directly reduces microbial populations during the preparation of fresh and cut produce. However, heat treatment alone was sufficiently effective to prevent any apparent difference between unsanitized (B-NC-H) and sanitized (B-C-H) heat-treated cluster grapes. In our previous work on fresh-cut grapes, hot water-treated samples had a lower decay rate than untreated samples during storage (Kou et al., 2007).

Visual evaluation. Maintenance of visual appearance of grapes during storage was significantly $(P<0.05)$ improved by hot water and or chlorine treatment and rachis removal (Fig. 3). Cluster grapes that received hot water treatment, with or without chlorine treatment, maintained a significantly 


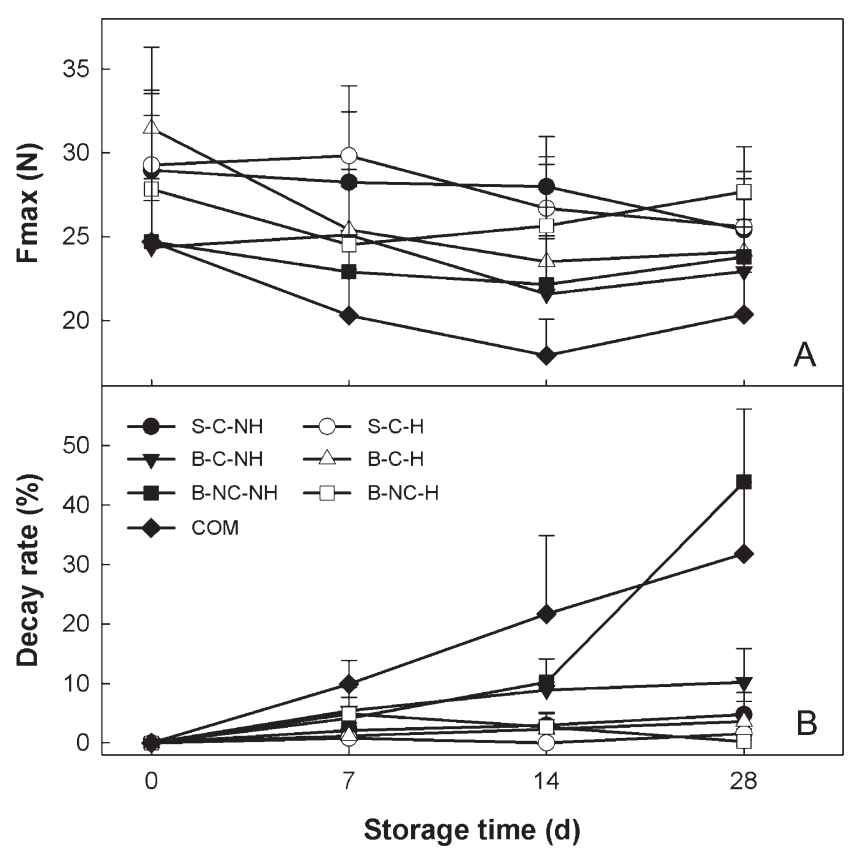

Fig. 2. Texture (A) and decay rate (B) of packaged short-stem and cluster grapes stored at $5{ }^{\circ} \mathrm{C}$. Vertical bars represent the SE of the mean of three replications. S-C-NH $=$ short-stem grapes that received chlorine wash and no heat treatment; S-C-H = short-stem grapes with chlorine wash and hot water treatment; $\mathrm{B}-\mathrm{C}-\mathrm{H}=$ cluster grapes that received chlorine and hot water treatment; $\mathrm{B}-\mathrm{C}-\mathrm{NH}=$ cluster grapes that received chlorine but no heat treatment; $\mathrm{B}-\mathrm{NC}-\mathrm{H}=$ cluster grapes that received no chlorine treatment but did receive hot water treatment; B-NC-NH = cluster grapes that did not receive either chlorine or hot water treatment.

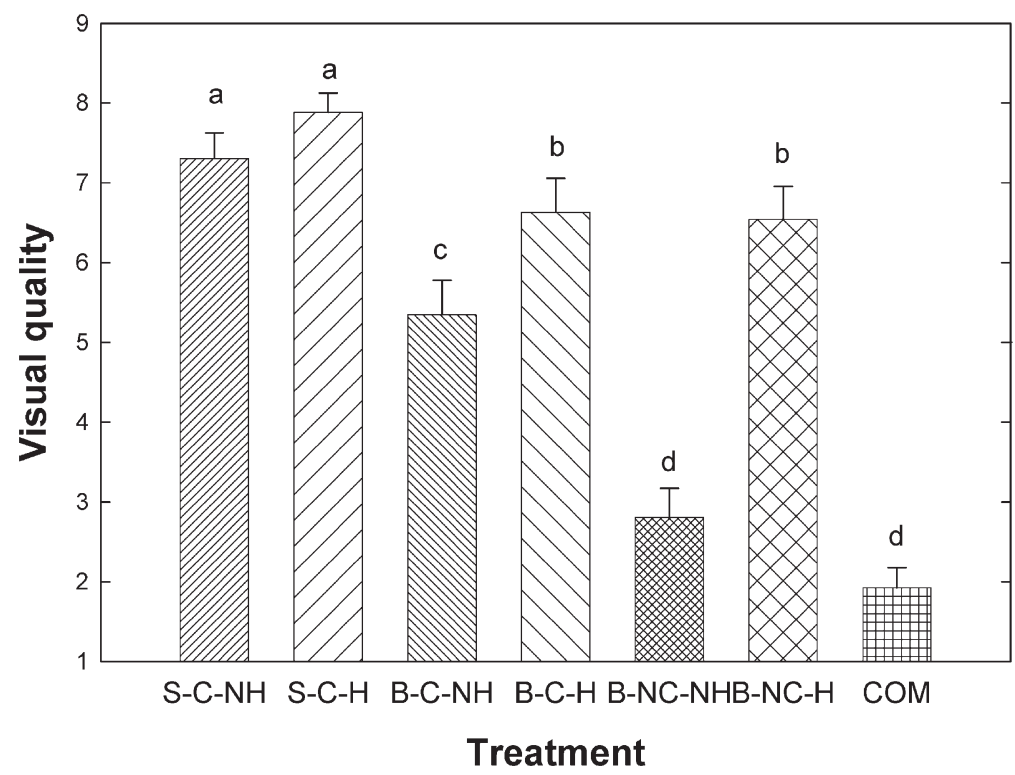

Fig. 3. Overall quality of short-stem and cluster grapes after $28 \mathrm{~d}$ of storage at $5{ }^{\circ} \mathrm{C}$. Vertical bars represent the SE of the mean of three replications. Treatments with different letters within the figure have significantly different mean visual quality scores $(P<0.05)$. S-C-NH $=$ short-stem grapes that received chlorine wash and no heat treatment; $\mathrm{S}-\mathrm{C}-\mathrm{H}=$ short-stem grapes with chlorine wash and hot water treatment; $\mathrm{B}-\mathrm{C}-\mathrm{H}=$ cluster grapes that received chlorine and hot water treatment; $\mathrm{B}-\mathrm{C}-\mathrm{NH}=$ cluster grapes that received chlorine but no heat treatment; $\mathrm{B}-\mathrm{NC}-\mathrm{H}=$ cluster grapes that received no chlorine treatment but did receive hot water treatment; B-NC-NH = cluster grapes that did not receive either chlorine or hot water treatment.

$(P<0.05)$ higher overall visual quality score than those that received no heat treatment on Day 28. The short-stem grapes, all of which received chlorine treatment, $(\mathrm{S}-\mathrm{C}-\mathrm{H})$ and $(\mathrm{S}-$ $\mathrm{C}-\mathrm{NH}$ ), had the highest overall visual quality scores, $7.9 \pm 0.56$ and $7.3 \pm 0.32$, for hot water-treated and nonhot water-treated grapes, respectively, and they appeared fresher and had less decay than others. The COM treatment exhibited the lowest overall quality at the end of storage followed by unsanitized (B-NC-NH) and sanitized (B-C-NH) cluster grapes as a result of decay development, rachis browning, loss of turgidity, and the loose connection of grape berries to pedicels. The rachis and pedicel desiccation of cluster grapes was observed at the end of 28-d storage at $5{ }^{\circ} \mathrm{C}$. Most rachis browning was noted on COM samples (data not shown), probably as a result of dehydration in the commercial packages. The quality deterioration of unsanitized grapes in MAP trays was probably caused by high humidity, which encouraged fungal growth.

In this study, we observed that hot water treatment was beneficial for maintaining fruit quality and extending shelf life. This could be partially the result of the improved protection against oxidative molecules engendered during fruit senescence or pathogen attack. In our previous work, all heat-treated grapes displayed higher antioxidant capacity than nonheat-treated grapes during storage (Kou et al., 2006a, 2006b).

Microbial growth. Among all treatments, grapes in MAP trays had significantly $(P<$ 0.05 ) lower lactic acid bacterial (LABORATORY) populations than COM grapes on Days 14 and 28 except for unsanitized cluster grapes (B-NC-NH) (Fig. 4A). A hot water treatment (B-NC-H) was significantly beneficial for maintaining lower LABORATORY populations on cluster grapes that received no sanitation treatment (B-NC-NH) after $28 \mathrm{~d}$ of storage. Similar trends were observed for aerobic mesophilic bacteria (Fig. 4B). However, although aerobic mesophilic bacterial growth for unsanitized cluster MAP grapes (B-NC-NH) was greater than for commercially packaged grapes on Day 7 , as the oxygen levels in the B-NC-NH packages declined, aerobic mesophilic bacterial growth in $\mathrm{COM}$ grapes overtook that in $\mathrm{B}$ NC-NH grapes by Day 14 and remained greater through Day 28 of storage.

Yeast and mold (Y\&M) populations increased during storage for all treatments (Fig. 4C). However, all heat-treated samples had less Y\&M growth during storage than those that received no heat treatment. The antifungal activity of hot water treatments in the range from 40 to $60{ }^{\circ} \mathrm{C}$ for times ranging from a few seconds at higher temperatures to several hours at the lower end of this temperature range have been demonstrated to be effective on a variety of commodities (Fallik, 2004; Lurie, 1998). Although hot water treatment reduces fungal pathogens and does induce resistance against pathogens in some commodities (Fallik, 2004), it does not prevent reinfection as do many chemical fungicides. Therefore, the combination of hot water treatment with packaging film to protect against reinfection from fungal pathogens in the environment and dehydration is beneficial for postharvest storage of many fruits. However, the more humid atmosphere resulting from storage in packaging film is conducive to growth of yeast and fungi. In this experiment, the yeast growth on unsanitized cluster MAP grapes (B-NC-NH) was 


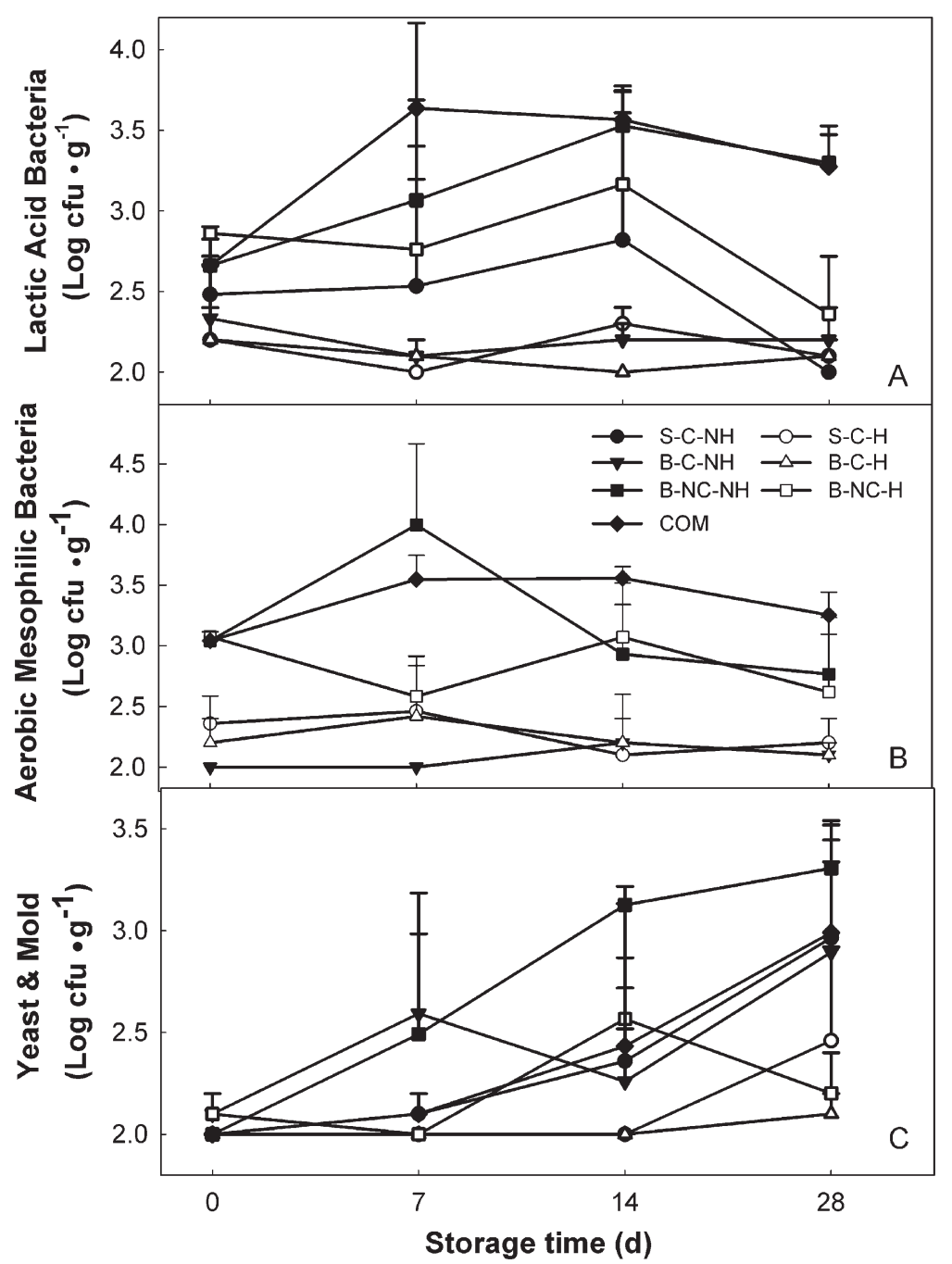

Fig. 4. Populations of lactic acid bacteria (A), aerobic mesophilic bacteria (B), and yeast \& mold (C) on short-stem and cluster grapes stored at $5{ }^{\circ} \mathrm{C}$. Vertical bars represent the SE of the mean of three replications. S-C-NH = short-stem grapes that received chlorine wash and no heat treatment; S-C-H = short-stem grapes with chlorine wash and hot water treatment; B-C-H = cluster grapes that received chlorine and hot water treatment; $\mathrm{B}-\mathrm{C}-\mathrm{NH}=$ cluster grapes that received chlorine but no heat treatment; $\mathrm{B}-\mathrm{NC}-\mathrm{H}=$ cluster grapes that received no chlorine treatment but did receive hot water treatment; B$\mathrm{NC}-\mathrm{NH}=$ cluster grapes that did not receive either chlorine or hot water treatment.

significantly $(P<0.05)$ higher than on COM grapes, probably as a result of higher humidity in the MA package. Yeast growth was inhibited by sanitizing grapes in chlorine solution. This result is in accordance with other studies that have demonstrated the antimicrobial activity of chlorine (Luo, 2007).

\section{Conclusions}

Hot water treatment at $45{ }^{\circ} \mathrm{C}$ for $8 \mathrm{~min}$ significantly $(P<0.05)$ improved the firmness and visual quality of grapes and reduced decay rate and Y\&M compared with controls. Rachis removal in combination with chlorine wash and MA packaging significantly $(P<0.05)$ extended the storage life and was beneficial for maintaining the visual quality of table grapes. Chlorine wash treatment significantly $(P<0.05)$ reduced microbial populations. The combination of these four treatments maintained excellent visual quality throughout the
Barkai-Golan, R. and D.S. Philips. 1991. Postharvest heat treatments of fresh fruits and vegetables for decay control. Plant Dis. 75: 1085-1089.

Cheah, L.H., D.E. Irving, A.W. Hunt, and V.K. Corrigan. 1992. Effect of hot water dips on Botrytis storage rot and quality of kiwifruit. Postharvest Biol. Technol. 2:1-6.

Crisoto, C.H. and F.G. Mitchell. 2002. Postharvest handling systems: Small fruits, p. 223-231. In: Kader, A.A. (ed.). Postharvest technology of horticultural crops. 3rd Ed. Univ. California Agric. Natural Resources, Oakland, CA.

Crisoto, C.H., J.L. Smilanick, and N.K. Dokoozlian. 2001. Table grapes suffer water loss, stem browning during cooling delays. Calif. Agr. 1: $39-42$.

Deng, Y., Y. Wu, Y. Li, M. Yang, C. Shi, and C. Zheng. 2007. Studies of postharvest berry abscission of 'Kyoho' table grapes during cold storage and high oxygen atmospheres. Postharvest Biol. Technol. 43:95-101.

Fallik, E. 2004. Prestorage hot water treatments (immersion, rinsing and brushing). Postharvest Biol. Technol. 32:125-134.

Fallik, E., S. Tuvia-Alkalai, X. Feng, and S. Lurie. 2001. Ripening characterisation and decay development of stored apples after a short prestorage hot water rinsing and brushing. Innov. Food Sci. Emerg. Technol. 2:127-132.

Franke, M. 2006. Post harvest technology for fresh grapes. 2 Oct. 2009. <http://www.transfresh. com/images up/Post_Harvest_Grape.pdf>.

Garcia, J.M., C. Anguilera, and M.A. Albi. 1995. Postharvest heat treatment on Spanish strawberry (Fragaria $\times$ ananassa cv. Tudla). J. Agr. Food Chem. 43:1489-1492.

Jacobi, K.K. and L.S. Wong. 1992. Quality of 'Kensington' mango (Mangifera indica Linn.) following hot water and vapor treatments. Postharvest Biol. Technol. 1:349-359.

Kim, J., Y. Luo, R.A. Saftner, and K.C. Gross. 2005. Delayed modified atmosphere packaging of fresh-cut Romaine lettuce: Effects on quality maintenance and shelf-life. J. Amer. Soc. Hort. Sci. 130:116-123.

Klein, J.D., J. Hanzon, P.L. Irwin, N. Ben-Shalom, and S. Lurie. 1995. Pectin esterase activity and pectin methyl esterification in heated Golden Delicious apples. Phytochem. 39:491494.

Kou, L., X. Liu, C. Zhang, and X. Geng. 2006a. Effects of respiratory intensity and storage quality of fresh-cut 'Kyoho' grape in hot water treatment. Food Fermentation Industries 32: 143-146 [in Chinese]. cially packaged grapes became decayed an their quality declined to a level that was unacceptable. The combination treatment was successful in reducing spoilage microbes, preventing dehydration, and delaying softening and senescence of fruits.

\section{Literature Cited}

Alique, R., J.P. Zamorano, M.A. Martínez, and J. Alonso. 2005. Effect of heat and cold treatments on respiratory metabolism and shelf-life of sweet cherry, type picota cv 'Ambrunés'. Postharvest Biol. Technol. 35:153-165.

Alonso, J., W. Canet, and T. Rodriguez. 1997. Thermal and calcium pretreatment affects texture, pectinesterase and pectic substances of frozen sweet cherries. J. Food Sci. 62:511515.

Artés-Hernández, F., F.A. Tomás-Barberán, and F. Artés. 2006. Modified atmosphere packaging preserves quality of $\mathrm{SO}_{2}$-free 'Superior Seedless' table grapes. Postharvest Biol. Technol. 39:146-154.
Kou, L., X. Liu, Y. Huang, W. Gao, and X. Yan. 2006b. Effect of heat treatment on protective enzymes and membrane lipid peroxidation of lightly processed 'Red Globe' grape. J. Chinese Ins. Food Sci. Technol. 6:111-115 [in Chinese].

Kou, L., Y. Luo, W. Ding, and X. Liu. 2007. Effects of mild heat treatment on microbial growth and product quality of packaged freshcut table grapes. J. Food Sci. 72:S567-S573.

Lamikanra, O., K.L. Bett-Garber, D.A. Ingram, and M.A. Watson. 2005. Use of mild heat pretreatment for quality retention of fresh-cut cantaloupe melon. J. Food Sci. 70:C53-C57.

Lamikanra, O. and M.A. Watson. 2007. Mild heat and calcium treatment effects on fresh-cut cantaloupe melon during storage. Food Chem. 102:1383-1388

Lara, I., P. García, and M. Vendrell. 2006. Postharvest heat treatments modify cell wall composition of strawberry (Fragaria ananassa Duch.) fruit. Scientia Hort. 109:48-53. 
Luna-Guzman, I., M. Cantwell, and D.M. Barrett. 1999. Fresh-cut cantaloupe: Effects of $\mathrm{CaCl}_{2}$ dips and heat treatments on firmness and metabolic activity. Postharvest Biol. Technol. 17:201-213.

Luo, Y. 2007. Fresh-cut produce wash water re-use affects water quality and packaged product quality and microbial growth. HortScience 42:1413-1419.

Lurie, S. 1998. Review postharvest heat treatments. Postharvest Biol. Technol. 14:257-269.

Lurie, S. and J.D. Klein. 1992. Calcium and heat treatments to improve storability of 'Anna' apples. HortScience 27:36-39.

Lurie, S., E. Pesis, O. Gadiyeva, O. Feygenberg, R. Ben-Arie, T. Kaplunov, Y. Zutahy, and A. Lichter. 2006. Modified ethanol atmosphere to control decay of table grapes during storage. Postharvest Biol. Technol. 42:222-227.

Lurie, S. and A. Sabehat. 1997. Prestorage temperature manipulations to reduce chilling injury in tomatoes. Postharvest Biol. Technol. 11:57-62.
Lydakis, D. and J. Aked. 2003. Vapour heat treatment of Sultanina table grapes. I: Control of Botrytis cinerea. Postharvest Biol. Technol. 27:109-116.

Madhukar, J. and S.M. Reddy. 1990. Control of fruit rot of guava by hot water treatment. Indian Phytopath. 43:234-236.

Meilgaard, M., G.V. Civille, and B.T. Carr. 1991 Sensory evaluation techniques. 2nd Ed. CRC Press Inc., Boca Raton, FL.

Paull, R.E. and N.J. Chen. 2000. Heat treatment and fruit ripening. Postharvest Biol. Technol. 21:21-37.

Perkins-Veazie, P.M., J.K. Collins, J. Lloid, and R.K. Striegler. 1992. Influence of package on postharvest quality of Oklahoma and Arkansas table grapes. Amer. J. Enol. Viticult. 43:79-82.

Sams, C.E., W.S. Conway, J.A. Abbott, R.J. Lewis, and N. Ben-Shalom. 1993. Firmness and decay of apples following postharvest pressure infiltration of calcium and heat treatment. J. Amer. Soc. Hort. Sci. 118:623-627.
Schirra, M., G. Barbera, S. D’Aquino, T. La Mantia, and R.E. McDonald. 1996. Hot dips and air temperature conditioning to improve shelf quality of late-crop cactus pear fruit. Trop. Sci. 36:159-165.

Schirra, M. and S. Ben-Yehoshua. 1999. Heat treatments: A possible new technology in citrus handling-challenges and prospects, p. 133-147. In: Schirra, M. (ed.). Advances in postharvest diseases and disorders control of citrus fruit. Research Signpost Publisher, Trivandrum, India.

Valero, D., J.M. Valverde, D. Martínez-Romero, F. Guillén, S. Castillo, and M. Serrano. 2006. The combination of modified atmosphere packaging with eugenol or thymol to maintain quality, safety and functional properties of table grapes. Postharvest Biol. Technol. 41:317-327.

Wu, Y., J. Ren, X. Hua, and Y. Liu. 1992. Postharvest berry abscission and storage of grape fruit. Acta Phytophysiol. Sinica 18:267-272 [in Chinese]. 